\title{
ACM/Springer Mobile Networks \& Applications (MONET) Guest Editorial for Special Issue on Innovative Computing Structures for Future Wireless Personal Networks
}

\author{
S. Smys ${ }^{1} \cdot$ Kamel A. Khaled ${ }^{2} \cdot$ Robert Bestak $^{3}$
}

Published online: 26 February 2016

(C) Springer Science+Business Media New York 2016

\section{Editorial}

Welcome to the Special Issue of the Mobile Networks and Applications Journal on Future Wireless Personal Networks. We have received a large number of wireless-related submissions to the journal. Wireless personal communication needs are extending beyond its limitations by gradually incorporating a wide range of challenging services and applications. These integrated network environments require innovative computing strategies to exploit the communication opportunity. Furthermore, mobility, quality of service and battery constrains increase the complexity of this task. In this context, what appears theoretically possible becomes conditionally feasible only when all available network resources are being

S. Smys

smys375@gmail.com

Karpagam College of Engineering, Coimbatore, India

TSU, Houston, TX, USA

3 Czech Technical University in Prague, Prague, Czech Republic efficiently exploited, including those hosted in nearby network architecture.

This special issue addresses the architecture issues with emphasis on wireless applications. The contributions to this special issue cover high-quality theoretical as well as practical works on a wide range of wireless issues. The contributed papers have been divided into three categories. The first category contains papers that deal with the performance improvements of wireless networks. The second group of papers in this issue deals with security issues in wireless systems. This group of papers offers solutions group security and user authentication. The third group of papers covers infrastructure issues of wireless networks.

We would like to thank the authors of the papers whose keen efforts and dedications made the publication of this special issue possible. We are indebted to the promptness and devotion of the reviewers whose valuable evaluations improved the quality of the papers significantly. In addition, we would like to thank the Springer publication staff members for their continuous support and dedication. We particularly appreciate the relentless support and encouragements granted to us by Dr. Imrich Chlamtac, the Editor-in-Chief of the Mobile Networks and Applications Journal. 


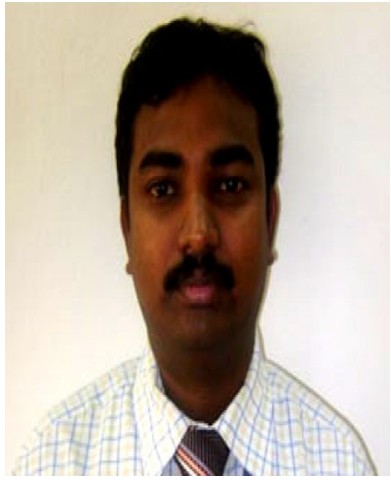

Dr. S.Smys received his M.E and Ph.D degrees all in Wireless Communication and Networking from Anna University and Karunya University, India. His main area of research activity is localization and routing architecture in wireless networks. He is served as a reviewer for IET, Springer, Inderscience and Elsevier journals. He has published many research articles in refereed journals and IEEE conferences. He has been the General chair, Session Chair, TPC Chair and Panelist in several conferences. He is member of IEEE and senior member of IACSIT wireless research group. He serves as Associate Editor of Computers and Electrical Engineering (C\&EE) journal, Elsevier and Guest Editor of Telecommunication system journal, Springer. He has been serving as Organizing Chair and Program Chair of several International conferences, and in the Program Committees of several International conferences. Currently he is working as a professor in the Department of Information Technology at Karpagam College of Engineering, Coimbatore, India.

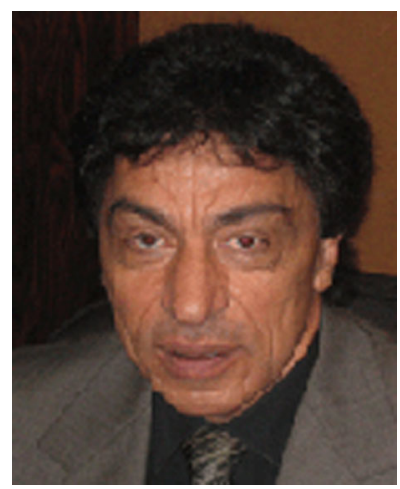

Dr. Kamel A. Khaled is currently a Professor of Computer Science at TSU. He worked as full time faculty and administrator for 22 years at the University of Louisville Engineering School. He was a Professor and the chair of the Computer Engineering and Computer Science department from August 1987 to January 2001. He also was the founding dean of the College of IT at the United Arab Emirates University and the College of CS \& IT at the Abu Dhabi University. Dr. Kamel received a BS in Electrical Engineering from Cairo University, a BS in
Mathematics from Ain Shams University, an MS in CS from Waterloo University, and a Ph.D. in ECE from the University of Cincinnati. Dr. Kamel worked as principle investigator on several government and industry grants. He also supervised over 100 graduate research Master and Doctoral students in the past 25 years. His current research interest is more interdisciplinary in nature but focuses on the use of IT in Industry and systems. Dr. Kamel's area of expertise is Computer Control, Sensory Fusion, and Distributed Computing. He recently published a book "Programmable Logic Controllers: Industrial Control" with McGrew Hill professional in August 2013.

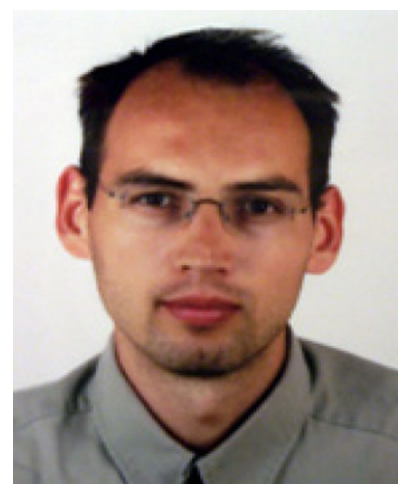

Dr. Robert Bestak obtained the $\mathrm{PhD}$ degree in Computer Science from ENST Paris, France (2003) and MSc degree in Telecommunications from Czech Technical University in Prague, CTU, (1999). Since 2004, he has been an Assistant Professor at Department of Telecommunication Engineering, Faculty of Electrical Engineering, and CTU. His main research interests include $4 / 5 \mathrm{G}$ networks, big data in mobile networks, and spectrum management. He is the Czech representative in the IFIP TC6 working group. He has served as journal editorial board member and steering and technical program committees member for numerous international journals and IEEE/IFIP conferences (Electronic Commerce Research journal, Networking, NGMAST, etc.). He participated in several national, EU (FP7-ROCKET, FP7-TROPIC), and third party founded research projects. 